\title{
ACTUARIAL PRESENT VALUE PADA ASURANSI LONG TERM CARE DALAM KASUS MULTISTATES
}

\author{
LOLANDA SYAMDENA, DODI DEVIANTO, HAZMIRA YOZZA \\ Program Studi S1 Matematika, \\ Fakultas Matematika dan Ilmu Pengetahuan Alam, Universitas Andalas, \\ Kampus UNAND Limau Manis Padang, Indonesia. \\ email : lolandasyamdena670@gmail.com
}

Diterima 14 Oktober 2019 Direvisi 21 Oktober 2019 Dipublikasikan 3 Desember 2019

\begin{abstract}
Abstrak. Biaya kesehatan yang sangat mahal menimbulkan kekhawatiran orang banyak terhadap proses penyembuhan penyakitnya, terutama untuk penderita penyakit kronis, sehingga mendorong sebagian orang untuk mengikuti asuransi kesehatan. Asuransi kesehatan merupakan salah satu bentuk pelayanan kesehatan yang proses pelayanannya terdiri dari banyak keadaan yang dapat berada pada kondisi yang membaik, tetap, atau memburuk jika dibandingkan dengan kondisi sebelumnya. Pada asuransi ini perhitungan premi bersih dapat dilakukan dengan menggunakan model perhitungan stokastik, yaitu model rantai Markov. Salah satu asuransi kesehatan yang menggunakan model rantai Markov untuk menghitung premi tunggal aktuaria adalah asuransi kesehatan Long Term Care $(L T C)$, yang dapat diikuti oleh peserta yang membutuhkan perawatan jangka panjang, seperti pasien penderita diabetes. Perpindahan keadan membaik atau memburuknya keadaan didefinisikan sebagai state, dan dapat dibuat diagram transisinya berdasarkan Diabetes Progresssion Model, yaitu Toleransi Glukosa Tergangggu (TGT), diabetes, komplikasi, dan meninggal. Peluang transisi dari suatu state ke state lainnya dapat dihitung dengan menggunakan metode Matriks Force of Transition yang membutuhkan nilai-nilai laju transisi pasien penderita diabetes, sehingga Actuarial Present Value-nya dapat dihitung secara parsial dari eleman-elemen matriks force of transition yang telah didapatkan.
\end{abstract}

Kata Kunci: Long Term Care, Multistates, Actuarial Present Value

\section{Pendahuluan}

Biaya kesehatan yang sangat mahal menimbulkan kekhawatiran orang banyak terhadap proses penyembuhan penyakitnya, terutama untuk penderita penyakit kronis yang proses perawatannya tidak bisa ditunda. Kekhawatiran inilah mendorong sebagian orang untuk mengikuti asuransi kesehatan untuk mengurangi risiko tersebut. Asuransi kesehatan merupakan salah satu bentuk pelayanan kesehatan yang proses pelayanannya terdiri dari banyak keadaan, dimana pada masing-masing keadaan pasien dapat berada pada kondisi yang membaik, tetap, atau memburuk jika dibandingkan dengan kondisi sebelumnya. Pada asuransi ini perhitungan premi bersih dapat dilakukan dengan menggunakan model perhitungan stokastik. 
Model perhitungan stokastik dapat dilakukan dengan menggunakan rantai Markov [3]. Salah satu asuransi kesehatan yang menggunakan model rantai Markov untuk menghitung premi tunggal aktuaria adalah asuransi kesehatan Long Term Care $(L T C)$. Asuransi ini adalah suatu jenis asuransi kesehatan yang dapat diikuti oleh peserta yang membutuhkan perawatan jangka panjang, baik perawatan di rumah ataupun perawatan medis tertentu seperti orang lanjut usia atau orang yang menderita penyakit kronis [7].

Suatu pelayanan perawatan dengan keadaan tertentu terhadap kondisi kesehatan peserta asuransi pada kasus ini dianggap sebagai state, sehingga dapat dikatakan bahwa asuransi LTC merupakan pelayanan perawatan yang terdiri dari banyak state paling tidak lebih dari dua state (multistates). Membaik atau memburuknya kondisi kesehatan peserta asuransi LTC diartikan sebagai perpindahan atau transisi dari satu state ke state lainnya. Pelayanan perawatan yang terdiri lebih dari satu layanan, menyebabkan permasalahan dalam menentukan nilai tunai atau Actuarial Present Value (APV) yang layak bagi perusahaan asuransi.

Perhitungan APV dengan menggunakan model Rantai Markov dibahas pada salah satu artikel yang ditulis oleh Bruce L. Jones (1994). Penerapan perhitungan APV ini dapat digunakan oleh perusahan asuransi kesehatan untuk peserta yang memiliki peluang penyakit diabetes. Data yang digunakan merupakan data asumsi yang dijelaskan dalam bentuk suatu kasus.

\section{Landasan Teori}

Penentukan eksponensial matriks bujursangkar didasarkan pada deret Taylor. Berikut adalah definisi terkait deret Taylor dan eksponensial matriks bujursangkar.

Definisi 2.1. [5] Misalkan untuk fungsi $f(x)$ terdefinisi disekitar $x=c$, dengan $f^{(n)}$ adalah turunan $k e-n$ dari $f(x)$, maka deret Taylor $f(x)$ didefinisikan sebagai:

$$
f(x)=\sum_{n=0}^{\infty} \frac{f^{(n)}(c)}{n !}(x-c)^{n} .
$$

Definisi 2.2. [5] Misalkan $A$ adalah matriks $n \times n$ dan matriks $A^{0}=I$, maka matriks eksponensial dari A yang dinotasikan dengan $e^{A}$ analog dengan deret Taylor dari fungsi skalar $e^{x}$, yaitu:

$$
e^{A}=I+A+\frac{A^{2}}{2 !}+\cdots+\frac{A^{k}}{k !}+\cdots=\sum_{k=0}^{\infty} \frac{A^{k}}{k !} .
$$

\subsection{Proses Stokastik dan Rantai Markov}

Definisi 2.3. [6] $S$ disebut ruang state, yang merupakan himpunan keadaan yang mungkin dilalui oleh suatu proses stokastik.

Definisi 2.4. [6] Proses stokastik $X=\left(X_{t}, t \in T\right)$ merupakan serangkaian peubah acak yang berubah terhadap waktu pengamatan, dimana $t \in T$ didefinisikan waktu dan $X_{t}$ memetakan suatu ruang contoh ke suatu ruang state terhadap waktu $t$. Jika 
indeks $T$ merupakan himpunan tercacah, maka $X$ disebut proses stokastik dengan waktu diskrit, dan jika indeks $T$ merupakan sebuah interval, maka $X$ disebut proses stokastik dengan waktu kontinu.

Definisi 2.5. [6] Rantai Markov dengan waktu diskret merupakan suatu proses stokastik $\left(X_{t}, t=0,1,2 ..\right)$ dengan ruang state $(1,2, \cdots, N)$, dimana untuk setiap $t \in\{0,1, \ldots\}$ berlaku $P\left(X_{t+1}=j \mid X_{t}=i, X_{t-1}=i_{t-1}, \cdots, X_{1}=i_{1}, X_{0}=i_{0}\right)=$ $P\left(X_{t+1}=j \mid X_{t}=i\right)$.

Definisi 2.6. [6] Rantai Markov dengan waktu kontinu merupakan suatu proses stokastik $\left(X_{t}, t \geq 0\right)$ dengan ruang state diskret, jika untuk setiap $s, t \geq 0 i, j, x \in$ $(1,2, \cdots, N)$ dan $0 \leq t<u$ berlaku $P\left(X_{t+s}=j \mid X_{s}=i, X_{u}=x, 0 \leq u \leq s\right)=$ $P\left(X_{t+s}=j \mid X_{s}=i\right)$.

Peluang transisi $p_{i j}$ harus memenuhi sifat sebagai berikut:

(1) $0 \leq p_{i j}, \leq 1, \forall i, j \geq 0$,

(2) $\sum_{j=1}^{N} p_{i j}=1$, untuk $i=1,2, \ldots, N$,

(3) $\lim _{s \rightarrow 0^{+}} P\left(X_{t+s}=j \mid X_{s}=i\right)=\left\{\begin{array}{l}1, i=j \\ 0, i \neq j\end{array}\right.$

Matriks peluang transisi 1 langkah dapat ditulis menjadi:

$$
P=\left[\begin{array}{cccc}
p_{11} & p_{12} & \cdots & p_{1 N} \\
p_{21} & p_{21} & \cdots & p_{2 N} \\
\vdots & \vdots & \vdots & \vdots \\
p_{N 1} & p_{N 1} & \cdots & p_{N N}
\end{array}\right]
$$

\subsection{Persamaan Chapman Kolmogorov dan Force of Transition}

\subsubsection{Persamaan Chapman Kolmogorov}

Persamaan Chapman-Kolmogorov merupakan sebuah metode untuk menghitung peluang transisi $n$-langkah, yaitu:

misalkan $n=t+m$, maka

$$
\begin{aligned}
p_{i j}^{(n)} & =P\left(X_{n}=j \mid X_{0}=i\right) \\
p_{i j}^{(t+m)} & =\sum_{k=0}^{\infty} P\left(X_{t+m}=j, X_{t}=k \mid X_{0}=i\right) \\
& =\sum_{k=0}^{\infty} p_{i k}^{(t)} p_{k j}^{(m)} \text { untukt }, n \geq 0 \geq \text { dani }, j \geq 0 .
\end{aligned}
$$

2.2.2. Force of transition

Definisi 2.7. [3] Force of transition (laju transisi) adalah suatu proses rantai Markov $\left(X_{t}\right)$ dengan ruang state $\{1,2,3, \cdots, N\}$ yang didefinisikan sebagai berikut:

$$
\mu_{i j}(t)=\lim _{s \rightarrow 0^{+}} \frac{p_{i j}(t+s)-p_{i j}(t)}{s}
$$


Lema 2.8. [3] Misalkan $\mu_{i j}(t)$ adalah force of transition (laju transisi) pada waktu $t$, dengan $i, j$ adalah state pada proses rantai Markov, maka sifat force of transition adalah :

$$
\sum_{j=1}^{N} \mu_{i j}(t)=0
$$

untuk $i=1,2, \cdots, N$ dan $t \geq 0$.

\subsubsection{Kolmogorov Maju}

Pada persamaan Kolmogorov maju, laju peluang transisi di waktu yang akan datang memiliki hubungan sebagai jumlah perkalian peluang transisi dengan laju dari peluang transisi sesaat (force of transition saat waktu mendatang), yaitu:

$$
\frac{d}{d t} P_{i j}(t)=\sum_{k=1}^{N} P_{i k}(t) \mu_{k j} .
$$

\section{Pembahasan}

\subsection{Model Matriks Force of Transition}

Misalkan $P(t)$ adalah matriks peluang transisi berukuran $N \times N$, matriks $Q$ adalah matriks force of transition berukuran $N \times N$, dan matriks $P^{\prime}(t)$ adalah matriks turunan pertama dari $P(t)$ berukuran $N \times N$, yaitu:

$$
\begin{gathered}
P(t)=\left[\begin{array}{cccc}
p_{11}(t) & p_{12}(t) & \cdots & p_{1 N}(t) \\
p_{21}(t) & p_{22}(t) & \cdots & p_{2 N}(t) \\
\vdots & \vdots & \cdots & \vdots \\
p_{N 1}(t) & p_{N 2}(t) & \cdots & p_{N N}(t)
\end{array}\right] \quad Q=\left[\begin{array}{cccc}
\mu_{11} & \mu_{12} & \cdots & \mu_{1 N} \\
\mu_{21} & \mu_{22} & \cdots & \mu_{2 N} \\
\vdots & \vdots & \cdots & \vdots \\
\mu_{N 1} & \mu_{N 2} & \cdots & \mu_{N N}
\end{array}\right], \text { dan } \\
P^{\prime}(t)=\left[\begin{array}{cccc}
p_{11}^{\prime}(t) & p_{12}^{\prime}(t) & \cdots & p_{1 N}^{\prime}(t) \\
p_{21}^{\prime}(t) & p_{22}^{\prime}(t) & \cdots & p_{2 N}^{\prime}(t) \\
\vdots & \vdots & \cdots & \vdots \\
p_{N 1}^{\prime}(t) & p_{N 2}^{\prime}(t) & \cdots & p_{N N}^{\prime}(t)
\end{array}\right]
\end{gathered}
$$

Berdasarkan persamaan Kolmogorov Maju 2.7, yaitu:

$$
\frac{d}{d t} p_{i j}(t)=\sum_{k=1}^{N} p_{i k}(t) \mu_{k j},
$$

sehingga dalam bentuk matriks, dapat ditulis sebagai:

$$
P^{\prime}(t)=P(t) Q \text {. }
$$

Untuk $t=0$, matriks peluang transisi $P(t)$ adalah $P(0)=I$, maka:

$$
P^{\prime}(0)=Q \text {. }
$$

Dengan mensubstitusikan persamaan (3.1), didapatkan:

$$
P^{\prime \prime}(t)=P(t) Q Q=P(t) Q^{2}
$$


Dengan demikian, bentuk deret Taylor dari $P(t)$ adalah:

$$
\begin{aligned}
P(t) & =P(0)+P^{\prime}(0) t+P^{\prime \prime}(0) t^{2}+P^{\prime \prime \prime}(0) t^{3}+\ldots \\
& =I+Q t+\frac{(Q t)^{2}}{2 !}+\frac{(Q t)^{3}}{3 !}+\ldots \\
& =e^{Q t}
\end{aligned}
$$

Misalkan $A$ adalah matriks yang kolom-kolomnya merupakan vektor eigen yang bebas linear dari Q, dan $D$ adalah matriks diagonal, sehingga:

$$
Q=A D A^{-1},
$$

sehingga dari persamaan (3.5) diperoleh

$$
\begin{aligned}
& P(t)=A\left[I+D t+\frac{D^{2} t^{2}}{2 !}+\frac{D^{3} t^{3}}{3 !}+\ldots\right] A^{-1}, \\
& P(t)=A\left[\begin{array}{cccc}
e^{d_{1} t} & 0 & \cdots & 0 \\
0 & e^{d_{2} t} & \cdots & 0 \\
\vdots & \vdots & \cdots & \vdots \\
0 & 0 & \cdots & e^{d_{k} t}
\end{array}\right] A=A e^{D t} A^{-1},
\end{aligned}
$$

jika diuraikan, maka elemen-elemen matriks $P(t)$ pada persamaan (3.9) adalah

$$
p_{i j}(t)=\sum_{k=1}^{N} a_{i k} e^{d_{k} t} c_{k i}
$$

dengan $n$ adalah banyak state, $a_{i j}$ adalah elemen matriks $A, c_{i j}$ adalah elemen matriks $A^{-1}$, dan $\mu_{i j}$ adalah elemen matriks eksponensial $e^{D t}$. Berdasarkan nilai $p_{i j}$ pada persamaan (3.10), permasalahan dalam mencari fungsi peluang transisi diganti dengan mencari nilai eigen dan vektor eigen dari matriks force of transition $[2]$.

\subsection{Actuarial Present Value pada Asuransi Long Term Care}

Actuarial Present Value atau premi tunggal merupakan pembayaran premi pada perusahaan asuransi yang dilakukan pada waktu kontrak asuransi disetujui dan selanjutnya tidak ada pembayaran lagi.

Jika $Z$ adalah rangkaian pembayaran premi, maka untuk menghitung Actuarial Present Value adalah [7]:

$$
E(Z)=\sum_{i=1}^{N-1} \sum_{l=1}^{N-1} \frac{a_{i l} c_{l i} b_{i}}{(\delta-d l)}+\sum_{i=1}^{N-1} \sum_{j=1}^{N} \sum_{l=l}^{N-1} \frac{a_{i l} c_{l i} \mu_{i j} b_{i j}}{(\delta-d l)}
$$

dengan $a_{i l}$ menyatakan elemen matriks $A$ yang merupakan matriks yang kolomkolomnya adalah vektor eigen dari matriks laju transisi $Q, c_{l i}$ menyatakan elemen matriks $C=A^{-1}$, dan $\mu_{i j}$ menyatakan elemen matriks $Q$ yang merupakan nilai laju transisi dari state $i$ ke state $j$. 


\subsection{Diagram Transisi Diabetes Progression Model}

Diabetes Progression Model adalah tahapan-tahapan penderita diabetes mellitus dari kondisi awal hingga kondisi terparah (meninggal dunia). Tahapan-tahapan tersebut yaitu [4]:

1. Toleransi Glukosa Terganggu (TGT)

Penderita TGT memiliki kadar gula darah post prandial (GDDP) 140-199 $\mathrm{mg} / \mathrm{dl}$.

2. Diabetes

Penderita TGT memiliki kadar gula darah post prandial (GDDP) > $200 \mathrm{mg} / \mathrm{dl}$

3. Komplikasi

Penderita diabetes melitus memiliki kadar glukosa yang dari waktu ke waktu dapat meningkat. Sehingga penderita diabetes nantinya akan mengalami gejala dari penyakit lain.

4. Meninggal Dunia

Berdasarkan Diabetes Progression Model, diagram transisinya adalah:

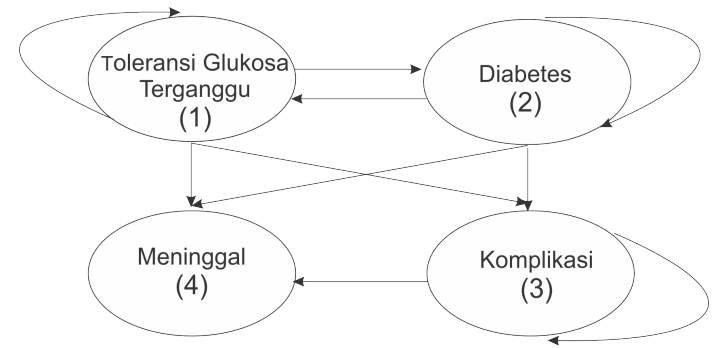

Gambar 1. Diagram Transisi Diabetes Progression Model

\subsection{Kasus}

Seorang berumur 50 tahun memiliki GDPP $160 \mathrm{mg} / \mathrm{dl}$ divonis menderita penyakit diabetes mengikuti asuransi Long Term Care. Benefit yang diterima setiap perpindahan state yang mungkin terjadi Rp. 5.000.000,- dan laju suku bunga $(\delta)$ saat itu adalah nol. Karena sulitnya informasi awal mengenai nilai-nilai laju transisi, maka data yang digunakan adalah data hipotesis laju transisi pada penderita penyakit diabetes, yang disajikan pada Tabel 1:

Tabel 1. Nilai-Nilai Laju Transisi Penderita Diabetes Berumur 50 Tahun

\begin{tabular}{|c|c|c|c|c|c|c|c|}
\hline State $i$ & 1 & 1 & 1 & 2 & 2 & 2 & 3 \\
\hline State $j$ & 2 & 3 & 4 & 1 & 3 & 4 & 4 \\
\hline Nilai Laju $\left(\mu_{i j}\right)$ & 0,21 & 0,05 & 0,07 & 0,09 & 0,18 & 0,07 & 0,3 \\
\hline
\end{tabular}


Berdasarkan sifat force of transition pada Lemma (2.8), maka nilai-nilai laju transisi pada tiap diagonalnya adalah: $\mu_{11}=-0,28 ; \mu_{22}=-0,34$; dan $\mu_{33}=-0,3$, dengan demikian matriks laju transisi yang entri-entrinya merupakan nilai-nilai laju transi penyakit diabetes pada seseorang yang berumur 50 tahun, dilambangkan dengan $Q^{(50)}$ dapat dituliskan menjadi:

$$
Q^{(50)}=\left[\begin{array}{cccc}
-0,28 & 0,21 & 0,05 & 0,02 \\
0,09 & -0,34 & 0,18 & 0,07 \\
0 & 0 & -0,3 & 0,3 \\
0 & 0 & 0 & 0
\end{array}\right]
$$

Nilai-nilai eigen dari matriks $Q$, yaitu $\lambda_{1}=-0,1692, \lambda_{2}=-0,4507, \lambda_{3}=-0,3$, $\lambda_{4}=0$. Karena nilai-nilai eigennya berbeda, maka matriks $Q$ dapat didiagonalkan. Selanjutnya dari nilai-nilai eigen akan ditentukan matriks $A$ yang merupakan matriks vektor eigen, $a_{1}, a_{2}, a_{3}$, dan $a_{4}$ merupakan vektor eigen dari $\lambda_{1}, \lambda_{2}, \lambda_{3}, \lambda_{4}$, dan matriks inversenya $A^{-1}$ yaitu:

$$
\begin{aligned}
A^{(50)}= & {\left[\begin{array}{cccc}
0,8845 & -0,8435 & -2,0203 & 1 \\
0,4663 & 0,6857 & -0,0456 & 1 \\
0 & 0 & 1 & 1 \\
0 & 0 & 0 & 1
\end{array}\right], A^{(50)-1}=} \\
& {\left[\begin{array}{cccc}
0,6858 & 0,8436 & 1,4240 & -2,9534 \\
-0,4663 & 0,8846 & -0,9018 & 0,4836 \\
0 & 0 & 1 & -1 \\
0 & 0 & 1 & 1
\end{array}\right] . }
\end{aligned}
$$

Berdasarkan Kasus 1, peserta asuransi berada dalam keadan Toleransi Glukosa Terganggu (TGT) yang artinya berada di state awal, yaitu state $i=1$. Berdasarkan Persamaan (3.2), dan diagram transisi pada Gambar (1) yang menggunakan state $N=4$, maka besarnya premi tunggal yang harus dibayarkan oleh peserta asuransi saat awal menjadi peserta asuransi yang berada pada state 1 dan menginginkan mendapatkan semua klaim manfaat untuk semua state adalah:

$$
\begin{aligned}
E(Z) & =\sum_{i=1}^{3} \sum_{l=1}^{3} \frac{a_{i l} c_{l i} b_{i}}{(\delta-d l)}+\sum_{i=1}^{3} \sum_{j=1}^{4} \sum_{l=l}^{3} \frac{a_{i l} c_{l i} \mu_{i j} b_{i j}}{(\delta-d l)} \\
& =57.309 .016,16,
\end{aligned}
$$

dengan $\mu_{i j}$ adalah elemen-elemen matriks $Q, a_{i j}$ adalah elemen-elemen matriks $A$, $\left[c_{i j}\right.$ adalah elemen-elemen matriks $A^{-1}$, dan $d_{i j}$ adalah elemen-elemen matriks $D$.

Perusahaan asuransi lakukan terhadap tertanggung saat kontrak sedang berlangsung yaitu, Membayarkan benefit sebesar Rp. 5.000.000,- kepada peserta asuransi, saat peserta asuransi berada pada state 1 , state 2 , dan state $3\left(b_{1}, b_{2}, b_{3}\right)$, saat peserta asuransi melakukan pemeriksaan kesehatan yang pertama pada state $i$ ia tetap berada pada state tersebut $\left(b_{11}, b_{22}, b_{33}\right)$, dan ketika kondisi kesehatan peserta asuransi berpindah dari state 1 ke 2, dari state 1 ke 3 , dari state 1 ke 4 , dari state 2 ke 1 , dari state 2 ke 3 , dari state 2 ke 4 , dari state 3 ke 1 , dari state 3 ke 2 , atau dari state 3 ke $4\left(b_{12}, b_{13}, b_{14}, b_{21}, b_{23}, b_{24}, b_{31}, b_{32}, b_{34}\right)$. 
Jika peserta asuransi hanya ingin dirawat sampai pada state 3 atau state 2 saja , artinya banyak state yang diikuti yaitu $N=3$ atau $N=2$, maka hasil perhitungan preminya untuk berbagai tingkat laju suku bunga $\delta=0, \delta=, .05 \delta=0,1$, disajikan pada Tabel 2:

Tabel 2. APV dengan Berbagai Laju Suku Bunga untuk Pelayanan hingga State 2, State 3, dan State 4

\begin{tabular}{|c|c|c|c|}
\hline Banyak State $(\mathrm{N})$ & $\delta=0$ & $\delta=0,05$ & $\delta=0,1$ \\
\hline 2 & $16.670 .472,61$ & $12.867 .901,300,-$ & $10.477 .875,06$ \\
3 & $38.911 .820,97$ & $31.386 .897,68$ & $26.457 .514,27$ \\
4 & $57.309 .016,16$ & $47.080 .002,40$ & $40.151 .616,40$ \\
\hline
\end{tabular}

Berdasarkan Tabel 2, dapat disimpulkan bahwa kenaikan laju suku bunga dari $\delta=0, \delta=0,05$, dan $\delta=0,1$ menyebabkan turunya $A P V$ yang harus dibayarkan oleh peserta asuransi kepada perusahaan asuransi.

\section{Kesimpulan}

Berdasarkan pembahasan yang telah dijelaskan, dapat disimpulkan bahwa:

(1) Dengan melakukan perhitungan secara parsial (state per-state), dapat diperoleh nilai APV yang harus dibayar peserta asuransi jika hanya ingin mememperoleh klaim sampai state tertentu ataupun memulai asuransi dari state tertentu, dimana kondisi-kondisi kesehatan peserta asuransi dijadikan sebagai statesnya.

(2) Nilai APV yang harus dibayarkan peserta asuransi kepada perusahaan asuransi semakin besar seiring semakin banyaknya state yang diikuti peserta.

(3) Kenaikan laju suku bunga menyebabkan turunya APV yang harus dibayarkan oleh peserta asuransi kepada perusahaan asuransi.

\section{Daftar Pustaka}

[1] Bain, L dan Max E. 1991. Introduction to Probability and Mathematical Statistic. Duxbury Press, California

[2] Hardi, F. 2018. Penentuan Peluang Transisi Model Select Ultimate Mortality Menggunakan Metode Matriks Force of Transition. Skripsi. Tidak diterbitkan . Bogor(ID): Institut Pertanian Bogor

[3] Jones BL. 1994. Actuarial Calculation of Using Markov Model: Transactions of Societ of Actuaries. 46: 227-250

[4] Kementerian Kesehatan RI. 2013. InfoDATIN Pusat Data dan Informasi Kementerian Kesehatan RI. Jakarta:Kementerian Kesehatan RI

[5] Leon, S.J. 1998. Aljabar Linear dan Aplikasinya.(Edisi ke-5). Terjemahan oleh Alit Bondan. Erlangga, Jakarta

[6] Ross, Sheldon M. 1982. Stochastic Process. United State of Amerika

[7] Ruswandi, R. 1982. Menentukan Nilai Premi Tunggal Aktuaria (Actuarial Present Value) pada Kasus Multi-State untuk Data CCRC. Jurnal Sains Teknologi. 11(3): $177-181$ 